\title{
Selenoprotein $\mathbf{W}$ redox-regulated $\mathrm{Ca}^{2+}$ channels correlate with selenium deficiency-induced muscles $\mathrm{Ca}^{2+}$ leak
}

\author{
Haidong Yao ${ }^{1, *}$, Ruifeng Fan ${ }^{1, *}$, Xia Zhao ${ }^{1}$, Wenchao Zhao ${ }^{1}$, Wei Liu' ${ }^{1,2}$, Jie Yang ${ }^{1}$, \\ Hamid Sattar ${ }^{1}$, Jinxin Zhao ${ }^{1}$, Ziwei Zhang ${ }^{1}$ and Shiwen $X_{u^{1}}$ \\ ${ }^{1}$ Department of Veterinary Medicine, Northeast Agricultural University, Harbin, P. R. China \\ 2 The Key Laboratory of Myocardial Ischemia, Harbin Medical University, Ministry of Education, Heilongjiang, P. R. China \\ * These authors have contributed equally to this work \\ Correspondence to: Shiwen Xu, email: shiwenxu@neau.edu.cn \\ Ziwei Zhang, email: zhangziwe@sina.com \\ Keywords: selenium deficiency; $\mathrm{Ca}^{2+}$ leak; selenoprotein $\mathrm{W}$; $\mathrm{Ca}^{2+}$ channels; redox regulation \\ Received: June 11,2016 Accepted: August 17, $2016 \quad$ Published: August 20, 2016
}

ABSTRACT

Selenium (Se) deficiency induces $\mathrm{Ca}^{2+}$ leak and calcification in mammal skeletal muscles; however, the exact mechanism is still unclear. In the present study, both Se-deficient chicken muscle models and selenoprotein W (SelW) gene knockdown myoblast and embryo models were used to study the mechanism. The results showed that Se deficiency-induced typical muscular injuries accompanied with $\mathrm{Ca}^{2+}$ leak and oxidative stress $(P<0.05)$ injured the ultrastructure of the sarcoplasmic reticulum (SR) and mitochondria; decreased the levels of the $\mathrm{Ca}^{2+}$ channels, SERCA, SLC8A, CACNA1S, ORAI1, STIM1, TRPC1, and TRPC3 $(P<0.05)$; and increased the levels of $\mathrm{Ca}^{2+}$ channel PMCA $(P<0.05)$. Similarly, SelW knockdown also induced $\mathrm{Ca}^{2+}$ leak from the SR and cytoplasm; increased mitochondrial $\mathrm{Ca}^{2+}$ levels and oxidative stress; injured SR and mitochondrial ultrastructure; decreased levels of SLC8A, CACNA1S, ORA1, TRPC1, and TRPC3; and caused abnormal activities of $\mathrm{Ca}^{2+}$ channels in response to inhibitors in myoblasts and chicken embryos. Thus, both Se deficiency and SelW knockdown induced $\mathrm{Ca}^{2+}$ leak, oxidative stress, and $\mathrm{Ca}^{2+}$ channel reduction. In addition, $\mathrm{Ca}^{2+}$ levels and the expression of the $\mathrm{Ca}^{2+}$ channels, RyR1, SERCA, CACNA1S, TRPC1, and TRPC3 were recovered to normal levels by $\mathrm{N}$-acetyl-L-cysteine (NAC) treatment compared with SelW knockdown cells. Thus, with regard to the decreased $\mathrm{Ca}^{2+}$ channels, SelW knockdown closely correlated Se deficiency with $\mathrm{Ca}^{2+}$ leak in muscles. The redox regulation role of SelW is crucial in Se deficiency-induced $\mathrm{Ca}^{2+}$ leak in muscles.

\section{INTRODUCTION}

Muscular dystrophy, such as white muscle disease (WMD) in animals and Keshan disease in humans [1], is a classical selenium (Se)/vitamin E deficiency disease $[2,3]$. Se deficiency either induces typical clinical and pathological changes or may cause various pathological responses at the molecular level of muscles [4]. Many attempts have been made to elucidate the mechanism of these disorders from different angles, including oxidative stress, apoptosis, inflammation response, disordered selenoproteins, or disrupted calcium $\left(\mathrm{Ca}^{2+}\right)$ signaling [2, $3,5]$. However, the initial molecular mechanism of $\mathrm{Se}$ deficiency-related muscle injuries still remains unclear.
$\mathrm{Ca}^{2+}$ plays important roles in the contraction, signal transduction, and enzyme active site in skeletal muscles [6]. In skeletal muscles, the influx and efflux of $\mathrm{Ca}^{2+}$ is regulated by several types of $\mathrm{Ca}^{2+}$ channels, including intracellular $\mathrm{Ca}^{2+}$-release channel: ryanodine receptor channel (RyR1, RyR3) and $\mathrm{Ca}^{2+}$ pump channel (SERCA); extracellular $\mathrm{Ca}^{2+}$-entry channels: L-type voltagedependent $\mathrm{Ca}^{2+}$ channel dihydropyridine receptors (DHPR or CACNA1S), transient receptor potential channels (TRPC1, TRPC3, and others), $\mathrm{Ca}^{2+}$-release-activated $\mathrm{Ca}^{2+}$ current channels (CRAC); and extracellular $\mathrm{Ca}^{2+}$-entry balancing channels: $\mathrm{Na}^{+} / \mathrm{Ca}^{2+}$ exchanger (NCX), plasma membrane $\mathrm{Ca}^{2+}$-ATPases (PMCA) and others [7]. The activities of these $\mathrm{Ca}^{2+}$ channels are closely related to 
the biological function of skeletal muscles and diseases of the muscles. Early observations demonstrated that the sarcoplasmic reticulum (SR) of Se deficiency muscle is defective in $\mathrm{Ca}^{2+}$ sequestration, resulting in extensive calcification of the muscle tissues [3]. $\mathrm{Ca}^{2+}$ disruption or $\mathrm{Ca}^{2+}$ channel inactivation in different types of cells was also correlated with disordered selenoproteins (SelN, SelT, SelK or SelM) [8-12], the executors of the biological function of Se. These pathological and molecular changes in muscles connect Se deficiency-related muscle injuries with $\mathrm{Ca}^{2+}$ signal disruption. However, the effect of $\mathrm{Se}$ deficiency on $\mathrm{Ca}^{2+}$ homeostasis has been less studied, and the mechanism of $\mathrm{Ca}^{2+}$ disruption in Se deficiency muscles still remains unclear. Although Se deficiency diseases models have been established in mice, pig, cow, lamb, and chicken [2, 3, 13, 14], whether the typical pathological changes, such as $\mathrm{Ca}^{2+}$ leak and calcification, in Se deficiency diseases can be replicated using currently available practical diets has yet to be determined.

Selenoprotein W (SelW) is the first selenoprotein linked to Se deficiency-related muscular disorders [15]. SelW is less abundant in the muscles of WMD animals, and WMD animals have demonstrated defective $\mathrm{Ca}^{2+}$ levels in the SR and calcification in muscles [3]. Therefore, SelW may have a close relationship with $\mathrm{Ca}^{2+}$ signals and
Se deficiency-related muscle damage. However, to the extent of our knowledge, there is still no direct report on the role of SelW in $\mathrm{Ca}^{2+}$ regulation or the link between SelW and $\mathrm{Ca}^{2+}$ disorder in Se deficiency muscles. Thus, we conducted the present study to determine 1) whether and how Se deficiency influences $\mathrm{Ca}^{2+}$ signals in chicken muscles and 2) whether SelW plays a role in the regulation of $\mathrm{Ca}^{2+}$ homeostasis in vitro and/or in vivo. The present study provides insights into the effects of Se and SelW on $\mathrm{Ca}^{2+}$ signaling and the physiological role of SelW in muscular dystrophy.

\section{RESULTS}

\section{Se deficiency-induced $\mathrm{Ca}^{2+}$ leak in chicken muscles}

In the present study, we treated the broiler chickens with a Se-deficiency diet for 25-30 days. During that time, the chickens demonstrated typical exudative diathesis, dyskinesia, extravasated blood in muscles, or even death (Figure 1A). To ensure that the Se deficiency models were successfully established, we also examined Se levels in muscles (unpublished data). At the molecular level, we

\section{A}
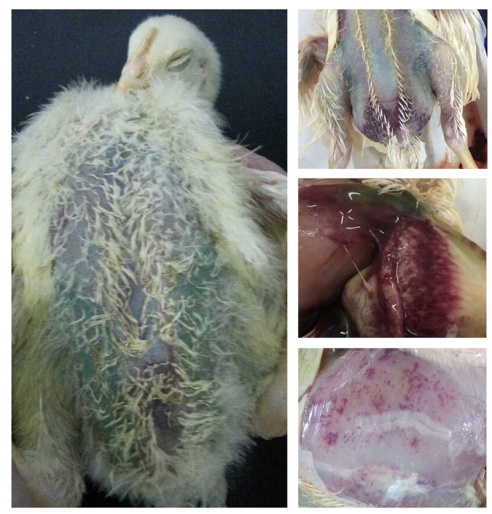

C

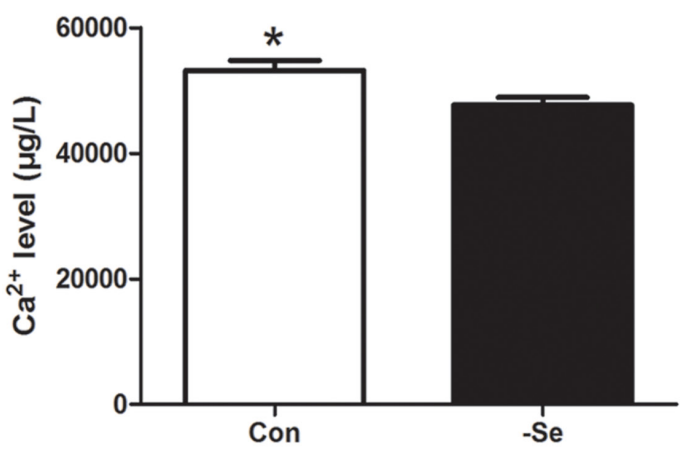

B
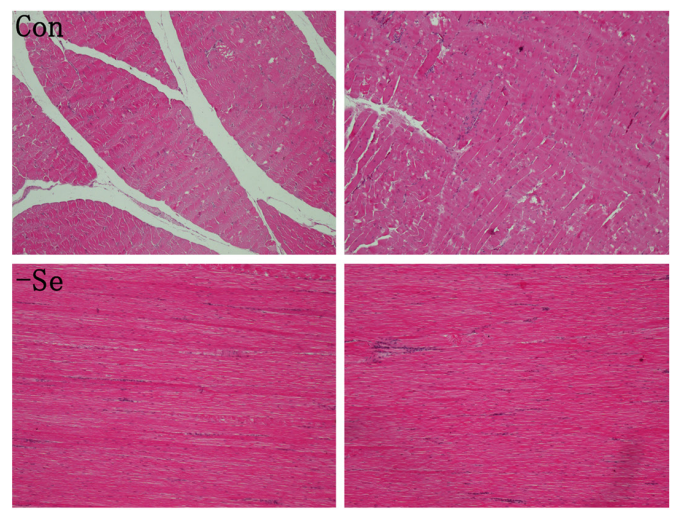

D
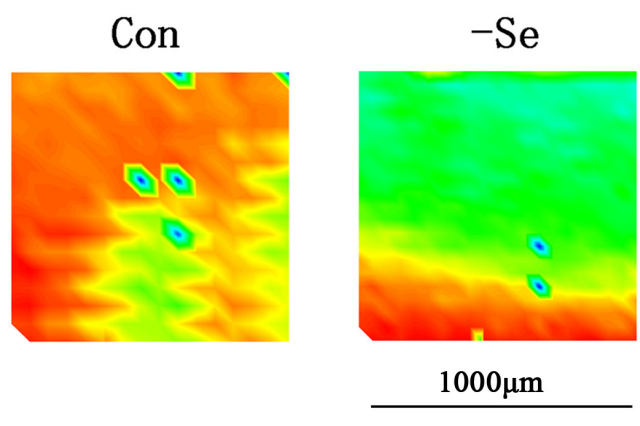

0.00

250.00

$\mathrm{Ca}$

Figure 1: Se-deficiency chicken muscles. A. The typical exudative diathesis and extravasated blood in muscles; B. HE staining for muscles, $100 \times$; C. the $\mathrm{Ca}^{2+}$ levels in chicken muscles; D. $\mathrm{Ca}^{2+}$ image detected by SR $\mu-\mathrm{XRF}$ technology where red showed the high $\mathrm{Ca}^{2+}$ levels and blue showed low $\mathrm{Ca}^{2+}$ levels. $\mathrm{Ca}^{2+}$ levels in chicken muscles were assessed using Student's $t$-test. The data are expressed as the means $\pm \mathrm{SD}, n=5$. * shows the significant difference, $P<0.05$. 
found disordered selenoproteins, oxidative stress, and apoptosis $[2,16]$. In agreement with previous reports, Se deficiency-related chicken disease can be successfully established by simply feeding a Se-deficient diet. As indicated by a previous study, $\mathrm{Ca}^{2+}$ leak and muscle calcification were always accompanied with muscle injuries in lamb [3]. In the present study, we detected total $\mathrm{Ca}^{2+}$ levels in the muscles using ICP-MS technology (Figure 1C) and found that the total $\mathrm{Ca}^{2+}$ levels were decreased by Se deficiency $(P<0.05)$. In addition, the distribution of $\mathrm{Ca}^{2+}$ in skeletal muscles by $\mathrm{SR} \mu-\mathrm{XRF}$ demonstrated lower $\mathrm{Ca}^{2+}$ levels in muscle sections (Figure 1D), which further verified $\mathrm{Ca}^{2+}$ leakage in Se-deficient muscles. No obvious calcification was observed by $\mathrm{HE}$ staining in either group (Figure 1B).

\section{$\mathrm{Ca}^{2+}$ levels in SelW deficiency chicken myoblasts}

In the present study, we silenced the expression of SelW by siRNA for $48 \mathrm{~h}$ and used different $\mathrm{Ca}^{2+}$ indicators to detect the $\mathrm{Ca}^{2+}$ levels in myoblasts. To verify the knockdown efficiency and exclude off-target effects, we previously constructed three different target siRNAs and two negatives [17], and the SelW expressions were decreased more than $77 \%$. In the present study, we used these validated siRNAs to treat myoblasts. These results demonstrated that SelW deficiency decreased the level of $\mathrm{Ca}^{2+}$ in cytoplasm (Figure 2A, Figure 2B) and SR (Figure 2A, Figure $2 \mathrm{C})(P<0.05)$ and increased $\mathrm{Ca}^{2+}$ levels in mitochondria (Figure 2A, Figure 2D) $(P<0.05)$. These data also support the hypothesis that SelW-related muscular disease is defective of $\mathrm{Ca}^{2+}$ levels in SR [3].

Following SelW deficiency, we treated cells with NAC, a global antioxidant. In our previous study, we showed that NAC treatment decreased ROS levels and apoptosis, following the SelW deficiency and the $\mathrm{H}_{2} \mathrm{O}_{2}$ treatments [17]. Therefore, NAC was an efficient antioxidant in primary culture myoblasts that alleviated the oxidative injuries. NAC treatment increased cytoplasmic $\mathrm{Ca}^{2+}$ (Figure 2A, Figure 2B) and decreased mitochondrial $\mathrm{Ca}^{2+}$ (Figure 2A, Figure 2D) to normal levels $(P<0.05)$ and alleviated the $\mathrm{Ca}^{2+}$ release from SR (Figure 2A, Figure 2C) $(P<0.05)$. These results demonstrated that NAC
A
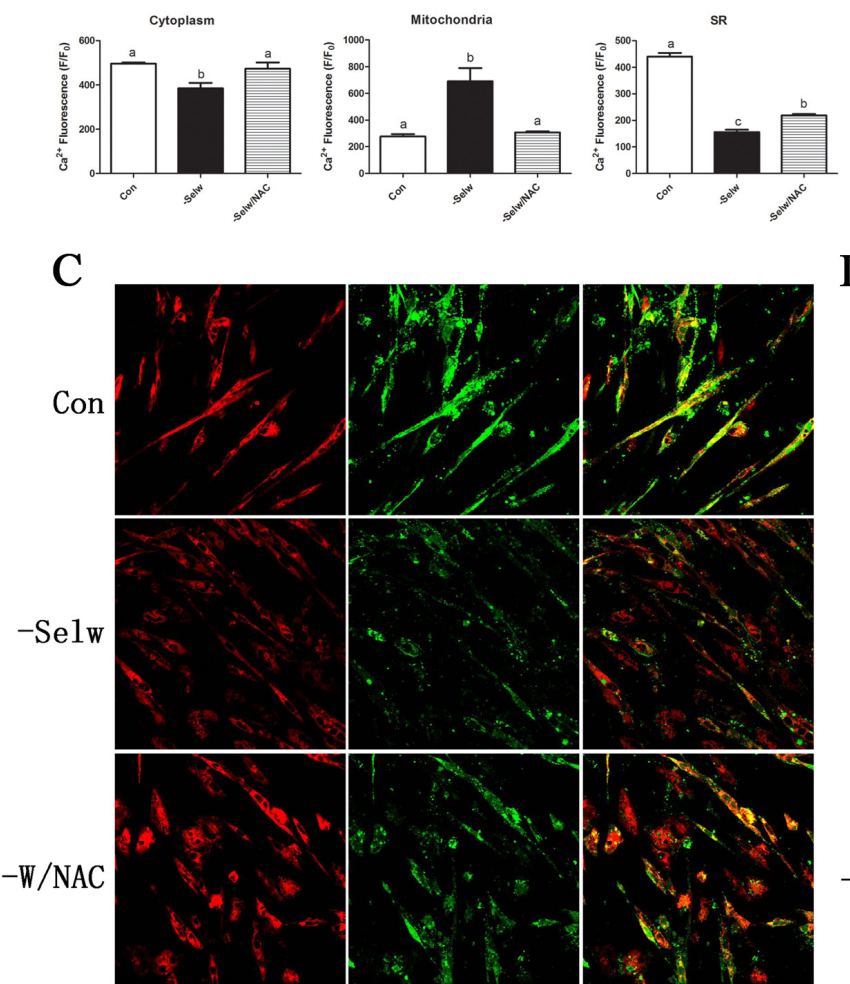

ER-Marker

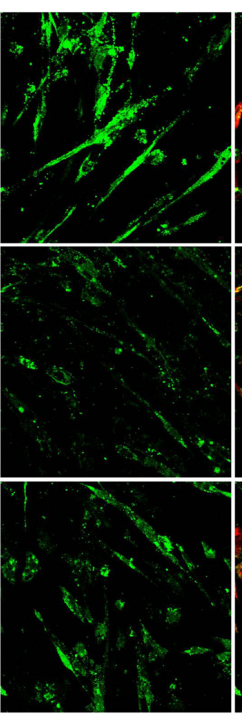

F1u5N

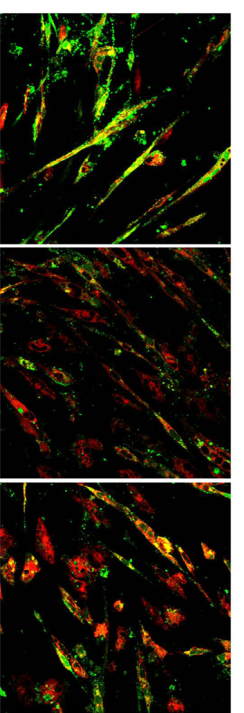

Merger

D

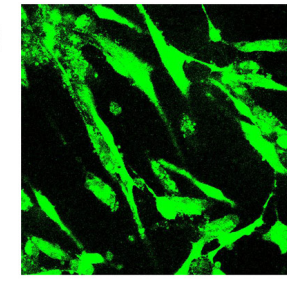

Con

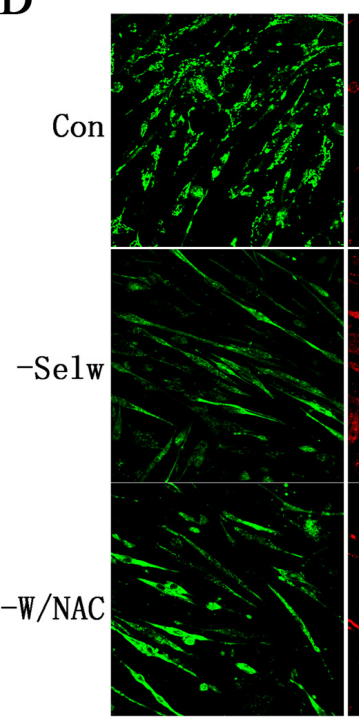

Mito-Marker

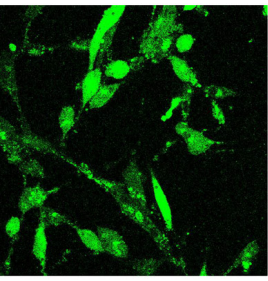

$-\mathrm{Selw}$

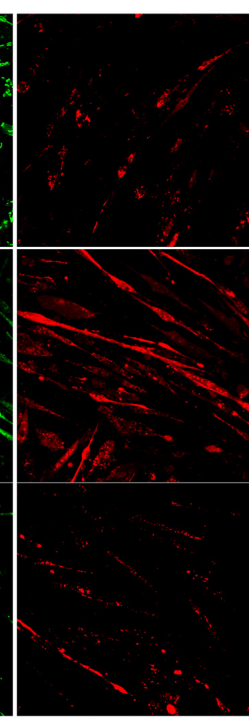

Rhod 2
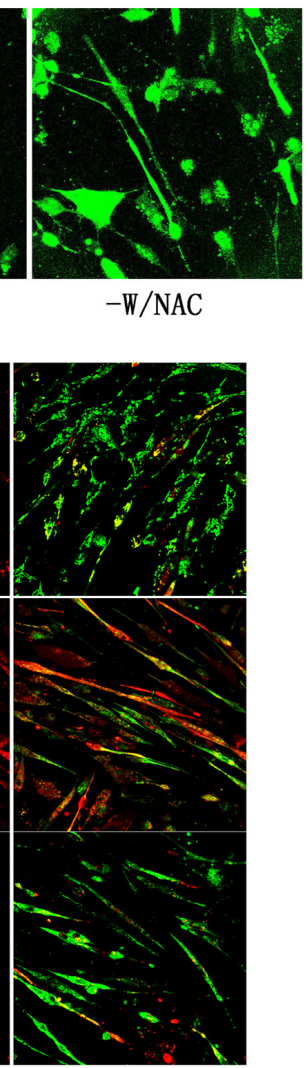

Merge

Figure 2: $\mathbf{C a}^{2+}$ levels detection. A. $\mathrm{Ca}^{2+}$ levels in myoblast; B. $\mathrm{Ca}^{2+}$ levels in cytoplasm detected by Fluo3 fluorescence; $\mathbf{C}$. $\mathrm{Ca}^{2+}$ levels in SR detected by Fluo5N fluorescence; D. $\mathrm{Ca}^{2+}$ levels in mitochondria detected by Rhod2 fluorescence. ER-Marker fluorescently labeled SR while Mito-Marker fluorescently labeled mitochondria. After the cell fluorescence was equilibrated and stabilized, the fluorescence was measured with a confocal laser scanning microscope using a 40× oil lens and analyzed using the Olympus Fluoview Ver. 2.0a Viewer software. The fluorescence intensity levels are presented relative to baseline and shown as $\mathrm{F} / \mathrm{F}_{0}$. At least $8-13$ cells were analyzed. Different lowercase letters show the significant difference, $P<0.05$. 
alleviated the effect of SelW deficiency $(P<0.05)$ in the cytoplasm and mitochondria. However, the $\mathrm{Ca}^{2+}$ signal in $\mathrm{SR}$ is still lower than the control $(P<0.05)$. Thus, SelW may partially influence the $\mathrm{Ca}^{2+}$ signal by regulating the oxidative stress.

\section{$\mathrm{Ca}^{2+}$ levels in SelW knockdown chicken embryo skeletal muscles}

To further identify the $\mathrm{Ca}^{2+}$ regulatory role of SelW on $\mathrm{Ca}^{2+}$ and the role of Se deficiency-related muscles on $\mathrm{Ca}^{2+}$ disruption, it was necessary to determine the role in vitro. In the present study, we injected the Cas9 SelW plasmid into a Stage X chicken embryo, collected the skeletal muscles at E7d embryo, and sequenced the transcript of SelW. The results (Figure 3A) demonstrated that in the CDS region of SelW, there is one deleted nucleotide. In addition, the knockdown efficiency (Figure $3 \mathrm{~B})$ was validated by western blot. The protein levels were decreased by more than $62 \%(P<0.05)$. Therefore, the SelW knockdown embryo models were established by Cas9 technology. Then, we screened the SelW knockdown models to check the levels of $\mathrm{Ca}^{2+}$ and other biomarkers. The results (Figure 4D) showed that, similar to myoblasts, SelW deficiency led the decrease of total $\mathrm{Ca}^{2+}$ levels in E7d embryo skeletal muscles $(P<0.05)$. The in vitro experiment further verified the role of SelW in the regulation of $\mathrm{Ca}^{2+}$ and that SelW deficiency was closely related to $\mathrm{Ca}^{2+}$ leak in muscles.

\section{Se deficiency influence $\mathrm{Ca}^{2+}$ channels expression in chicken muscles}

In the present study, we detected $10 \mathrm{Ca}^{2+}$ channels: including RyR1, RyR3, SERCA1s, TRPC1, TRPC3, CACNA1S, CRAC (STIM1, ORAI1), NCX (SLC8A1), and PMCA1 (Figure 4A and Figure 4E). Se deficiency induced the decrease of SERCA, SLC8A, CACNA1S, ORAI1, STIM1, TRPC1, and TRPC3 $(P<0.05)$ and the increase of PMCA $(P<0.05)$, but it did not influence RyR1 or RyR3 $(P>0.05)$. All extracellular $\mathrm{Ca}^{2+}$-entry channels were decreased, while intracellular $\mathrm{Ca}^{2+}$-release channels were not influenced. Lower levels of extracellular $\mathrm{Ca}^{2+}$ entry channels decrease the $\mathrm{Ca}^{2+}$ transporting activities, but higher PMCA, lower SERCA, and unchanged RyR1 and RyR3 keep $\mathrm{Ca}^{2+}$ leak from SR. Thus, taking into account the lower levels of total muscle $\mathrm{Ca}^{2+}$ levels, it is reasonable to hypothesize that $\mathrm{Se}$ deficiency induced $\mathrm{Ca}^{2+}$ leak in muscles by influencing $\mathrm{Ca}^{2+}$ channels.

\section{SelW deficiency influenced the expression of $\mathrm{Ca}^{2+}$ channels in chicken myoblasts}

In chicken myoblasts, SelW deficiency (Figure 4B, Figure 4E) decreased the levels of RyR1, RyR3, CACNA1S, SERCA1, TRPC1, TRPC3, STIM1, SERCA1, and ORAI1 $(P<0.05)$ but did not influence SLC8A1 or PMCA Ca ${ }^{2+}$ channels $(P>0.05)$. Thus, the effect of SelW deficiency on $\mathrm{Ca}^{2+}$ channels (CACNA1S, SERCA, TRPC1, TRPC3, STIM1, and ORAI1) was the same as Se deficiency in muscles.

To identify the effect of SelW on $\mathrm{Ca}^{2+}$ channels, we also treated myoblasts with the specific $\mathrm{Ca}^{2+}$ channel inhibitors (ryanodine for RyR1; thapsigargin for SERCA; Cd for CACNA1S; and Ni for SLC8A1) and activator (caffeine for RyR1). After the cell fluorescence was equilibrated and stabilized, we treated the cells with different inhibitors and activators separately and observed the cellular response. The results (Figure 5) demonstrated that the response of cells to caffeine was not significantly different than control and siRNA cells; however, the effects of ryanodine, $\mathrm{Ni}$, thapsigargin, and $\mathrm{Cd}$ on cells were different. When treated with ryanodine, control cells showed a sustained increase in $\mathrm{Ca}^{2+}$ signal, while in siRNA cells, the $\mathrm{Ca}^{2+}$ levels remained stable, Therefore, the inhibiting effect of ryanodine on control cells was more significant than siRNA cells. Both groups of cells showed rapid responses to thapsigargin and then reduced to a lower level. However, siRNA cells recovered to the normal levels earlier (more than $25 \mathrm{~s}$ ) than control and were even reduced to a lower level than normal levels. Therefore, the sensitivity of SERCA to thapsigargin is increased in siRNA SelW. Ni treatment induced a higher and more rapid response in control cells with shorter duration than siRNA cells. Ni treatment maintained a higher $\mathrm{Ca}^{2+}$ level in siRNA cells. In siRNA cells, the NCX (SLC8A1) channels showed a sustained response to Ni. Cd treatment decreased the $\mathrm{Ca}^{2+}$ levels in siRNA cells, but did not influence $\mathrm{Ca}^{2+}$ levels in control cells. SelW deficiency increased the sensitivity of cells to $\mathrm{Cd}$ treatment. Thus, excepting the inhibitory effect of SelW deficiency on the expression of $\mathrm{Ca}^{2+}$ channels, SelW deficiency also influenced the activities of RyR1, SERCA, CACNA1S, and SLC8A1 in myoblasts.

In addition, after the treatment of $\mathrm{NAC}$, the $\mathrm{Ca}^{2+}$ channels were also influenced by SelW deficiency. NAC treatment increased RyR1, CACNA1S, TRPC1, and TRPC3 to a normal or higher level (Figure 4B) $(P<0.05)$ and alleviated the effect of SelW deficiency on RyR3, SERCA, and STIM1 $(P<0.05)$. Therefore, the effect of SelW on $\mathrm{Ca}^{2+}$ channels was partially dependent on the redox-regulation role. 
A

GGCGACGGCTTCGTGGACACC--ACGCCAAACTGCAGCGCATCGTGGCCGCCAT-1.

GGCGACGGCTTCGTGGACACCGACGCCAAACTGCAGCGCATCGTGGCCGCCAT.WT

B
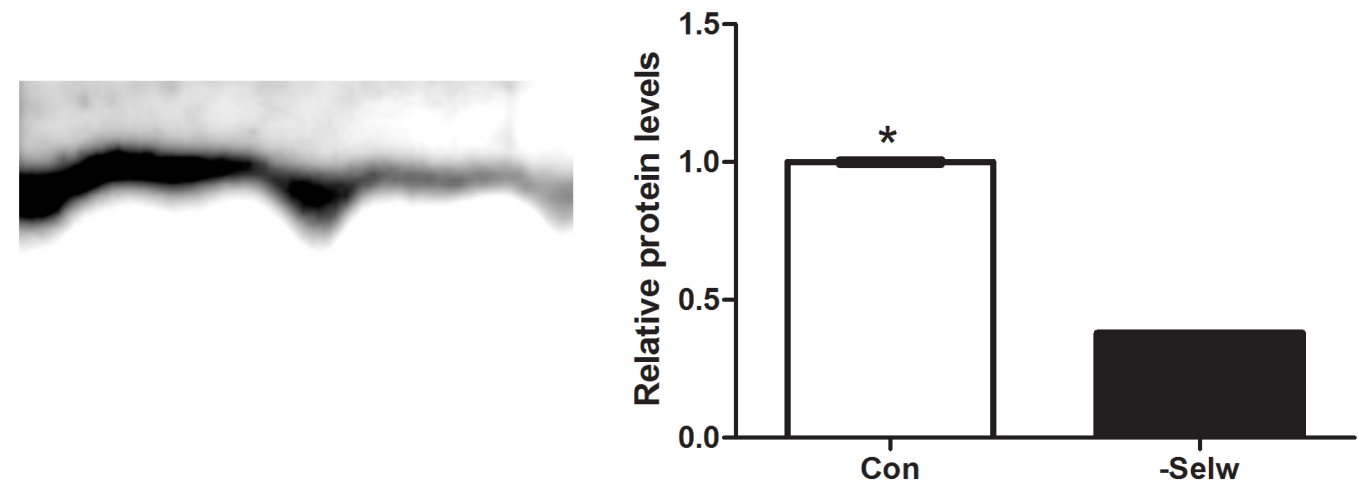

Figure 3: The sequence of SelW in embryo. A. The sequences of SelW from SelW-knockdown embryo muscles. Deletions are indicated with (--); B. the proteins levels of SelW where $\beta$-actin was selected as the reference and the related proteins levels were assessed using Student's $t$-test. The data are expressed as the means $\pm \mathrm{SD}, n=5$, * shows the significant difference, $P<0.05$.
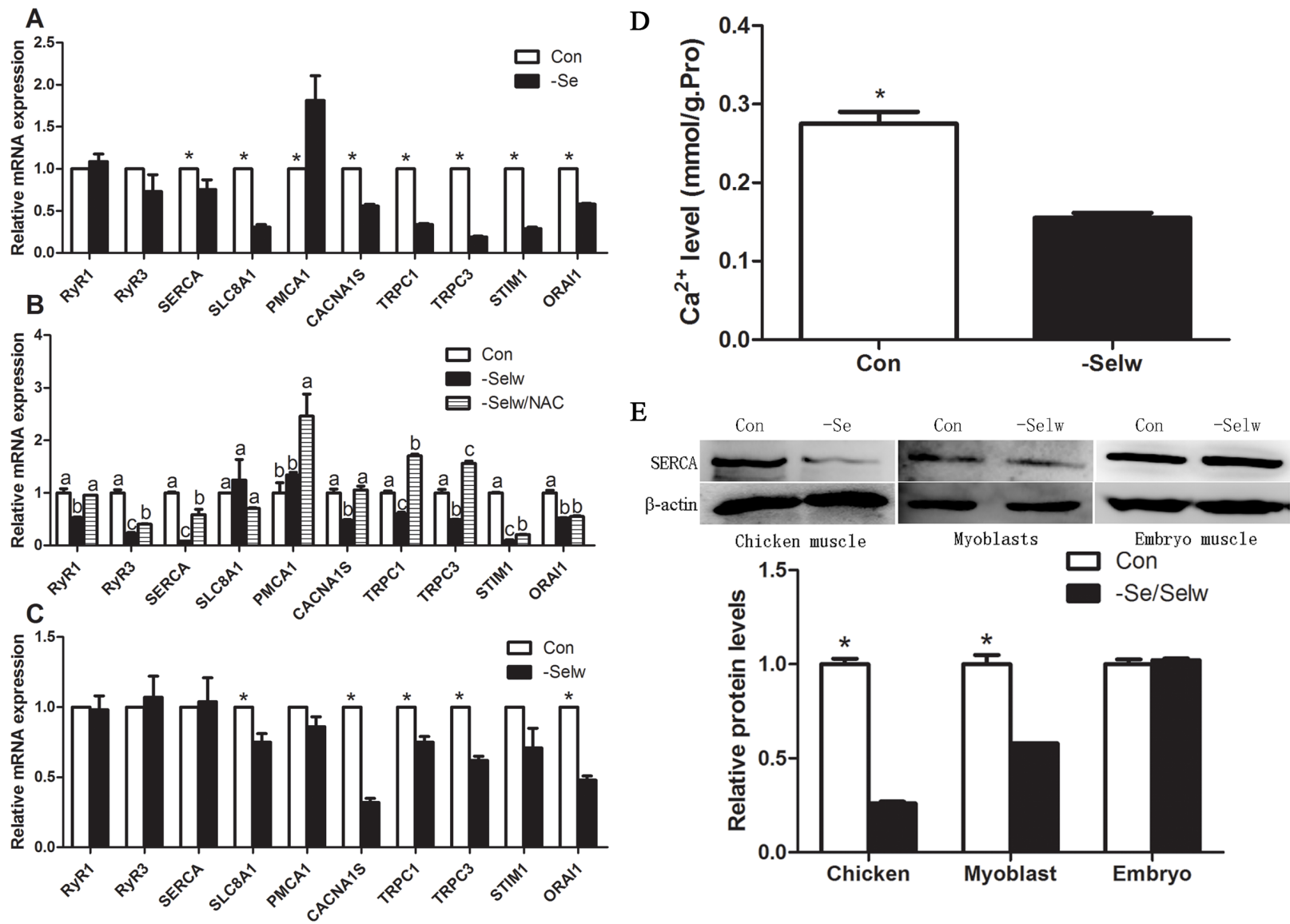

Figure 4: The expression levels of $\mathrm{Ca}^{2+}$ channels and $\mathrm{Ca}^{2+}$ levels in embryo muscles. A. mRNA levels of $\mathrm{Ca}^{2+}$ channels in chicken muscles; B. mRNA levels of $\mathrm{Ca}^{2+}$ channels in myoblasts; $\mathbf{C}$. mRNA levels of $\mathrm{Ca}^{2+}$ channels in embryo muscles; $\mathbf{D}$. $\mathrm{Ca}^{2+}$ levels in embryo muscles; E. the protein levels of SERCA1S were detected by western blot technology and $\beta$-actin was selected as the reference. $\mathrm{Ca}^{2+}$ channels in chicken muscles, $\mathrm{Ca}^{2+}$ levels in embryo muscles, and protein levels of $\mathrm{Ca}^{2+}$ channels were assessed using Student's $t$-test while $\mathrm{Ca}^{2+}$ channels in myoblasts were assessed using one-way ANOVA. The data are expressed as the means $\pm \mathrm{SD}, n=5, *$ and different lowercase letters shows the significant difference, $P<0.05$. 


\section{SelW deficiency influenced the expression of $\mathrm{Ca}^{2+}$ channels in embryo muscles}

Similar to the Se deficiency muscles, we also detected $10 \mathrm{Ca}^{2+}$ channels in embryo muscles. The results (Figure 4C and Figure 4E) showed that SelW knockdown decreased the levels of SLC8A, CACA1S, ORA1, TRPC1, and TRPC3 $(P<0.05)$, but other $\mathrm{Ca}^{2+}$ channels were not influenced $(P>0.05)$. It was observed that SelW influenced less $\mathrm{Ca}^{2+}$ channels than Se deficiency, but the effect of SelW knockdown on $\mathrm{Ca}^{2+}$ channels (SLC8A1, CACNA1S, TRPC1, TRPC3, and ORAI1) was similar. In the in vivo experiment, SelW primarily decreased the levels of extracellular $\mathrm{Ca}^{2+}$-entry channels, similar to $\mathrm{Se}$ deficiency.

\section{Antioxidative enzyme activity and oxidative injuries}

To examine the redox state in chicken and embryo, we detected the activities of antioxidative enzymes GPx, SOD, and CAT and measured $\mathrm{H}_{2} \mathrm{O}_{2}$ and MDA levels. The results (Figure 6A) showed that Se deficiency decreased the activities of GPx, SOD, and CAT while increasing $\mathrm{H}_{2} \mathrm{O}_{2}$ and MDA levels in chicken muscles $(P$ $<0.05$ ). However, in embryo muscle (Figure $6 \mathrm{~B}$ ), SelW knockdown decreased the activity of CAT only $(P<$ $0.05)$, not GPx and SOD $(P>0.05)$. The $\mathrm{H}_{2} \mathrm{O}_{2}$ and MDA levels were increased $(P<0.05)$. In our previous study, we also detected the ROS concentration, MDA levels, and antioxidative enzymes in myoblasts, which showed oxidative stress in SelW-silenced myoblasts $[16,17]$.
Therefore, both Se deficiency and SelW knockdown induced oxidative stress.

\section{Ultrastructure detected by electron microscopy}

In the present study, we detected the ultrastructure of chicken muscles, myoblast, and embryo muscles. The results (Figure 7) demonstrate that Se and SelW deficiencies primarily induced swelling and dilation in both SR and mitochondria, vacuolization, and disruption of the mitochondrial cristae, which has been shown to be closely related to $\mathrm{Ca}^{2+}$ leak and oxidative stress [18]. Myoblasts were also treated with NAC, and it was found that NAC alleviated the histopathological alterations in SR and mitochondria.

\section{Mitochondrial membrane potential in myoblasts}

Mitochondrial membrane potential $(\Delta \Psi \mathrm{m})$ is always influenced by substantial amounts of cytosolic $\mathrm{Ca}^{2+}$ and mitochondrial $\mathrm{Ca}^{2+}$. In the present study, we measured $\Delta \Psi \mathrm{m}$ using two different technologies. Both results (Figure 8) showed that SelW deficiency deceased $\Delta \Psi \mathrm{m}(P$ $<0.05)$, while the NAC treatment alleviated the $\Delta \Psi \mathrm{m}(P$ $<0.05)$. Similar to previous studies, which demonstrated that excessive $\mathrm{Ca}^{2+}$ accumulation in mitochondria induced mitochondrial dysfunction and injury, $\Delta \Psi \mathrm{m}$ was also influenced by the treatment of NAC $[18,19]$. Therefore, the redox regulation function of SelW plays important role in the mitochondrial injuries.
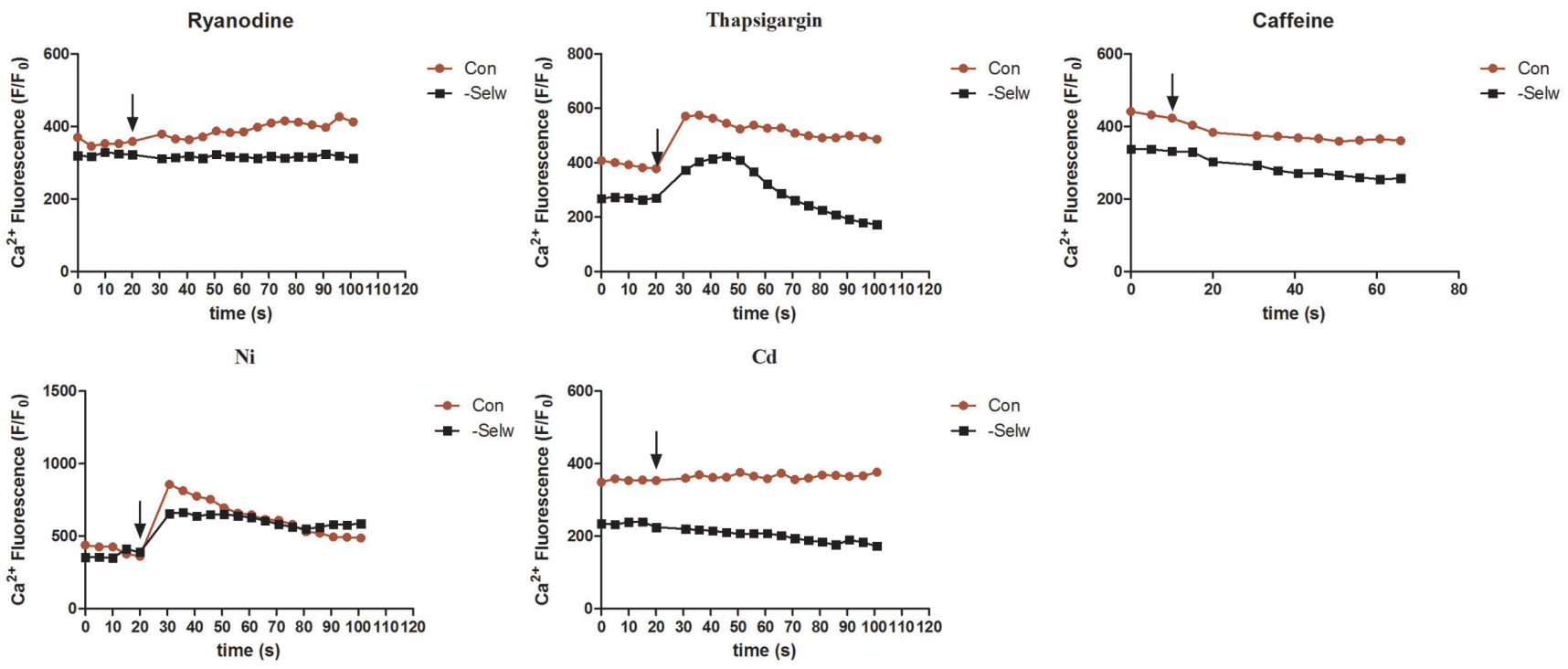

Figure 5: The $\mathrm{Ca}^{2+}$ levels following the treatment with inhibitors and activators. After the cell fluorescence was equilibrated and stabilized, Ni, Ryanodine, Cd, Caffeine, Thapsigargin were used to treat the cells, and the fluorescence changes measured. At least 8-13 cells were analyzed, $n=5$. 


\section{DISCUSSION}

$\mathrm{Ca}^{2+}$ leak and calcification in skeletal muscles was reported in Se deficiency-related muscular dystrophy [3], which indicates the involvement of $\mathrm{Ca}^{2+}$ disorder in Se deficiency muscle injuries. However, fewer reports demonstrated the effect of Se deficiency on $\mathrm{Ca}^{2+}$ signal in animals, and the mechanism by which pathological changes occur. In chicken, we successfully replicated Se deficiency-related muscle disease and observed the typical pathological and molecular changes, such as oxidative stress, apoptosis, disordered selenoproteins [2, 20], SR, and mitochondrial injuries; and $\mathrm{Ca}^{2+}$ leak was reported only in lamb [3]. The present study supported
A

GPx
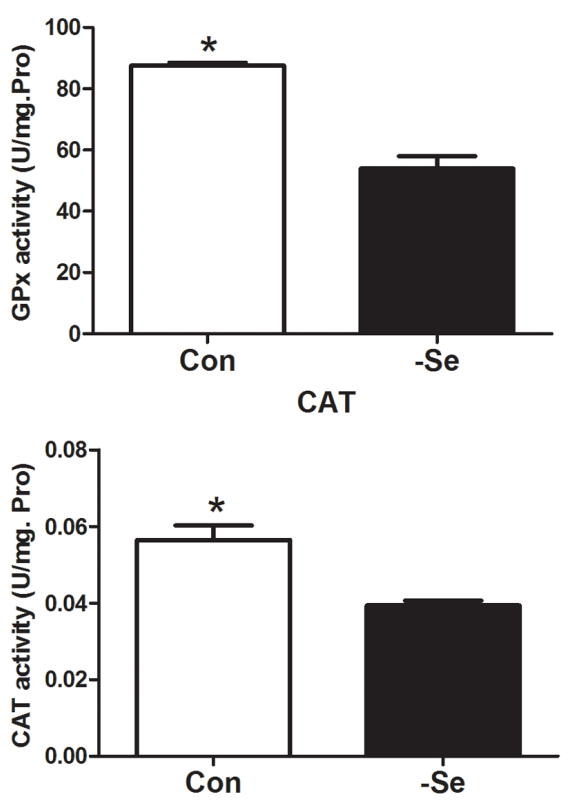

B

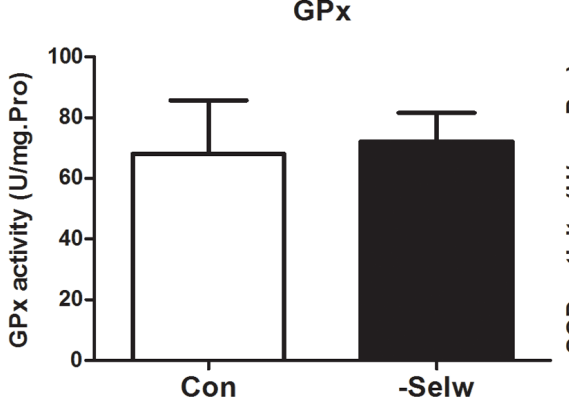

CAT

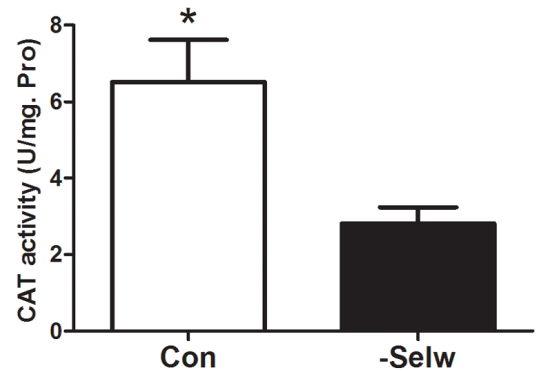

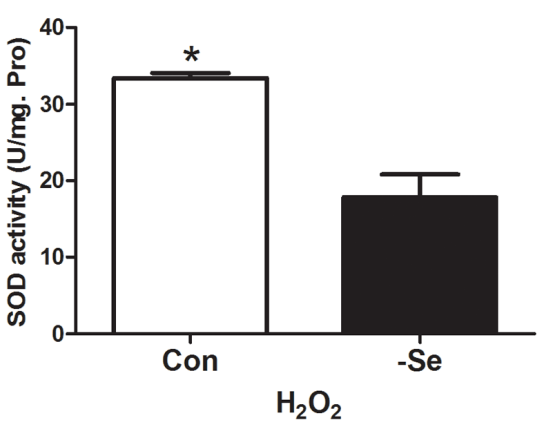
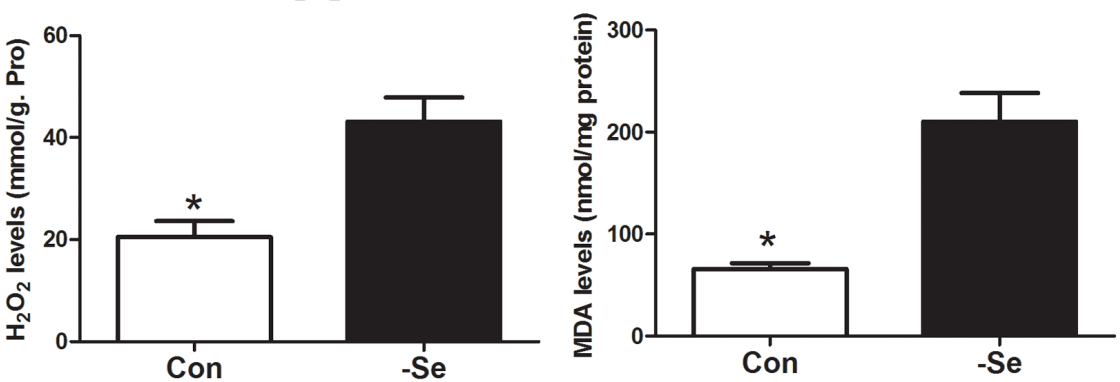

SOD

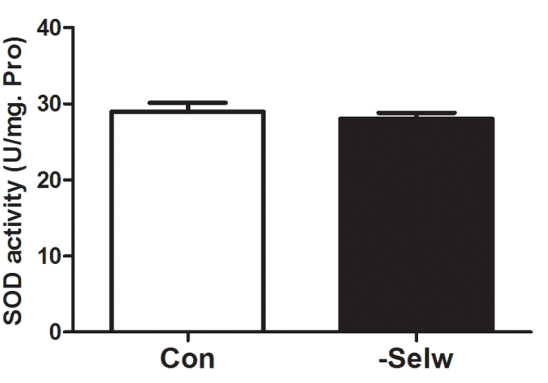

$\mathrm{H}_{2} \mathrm{O}_{2}$
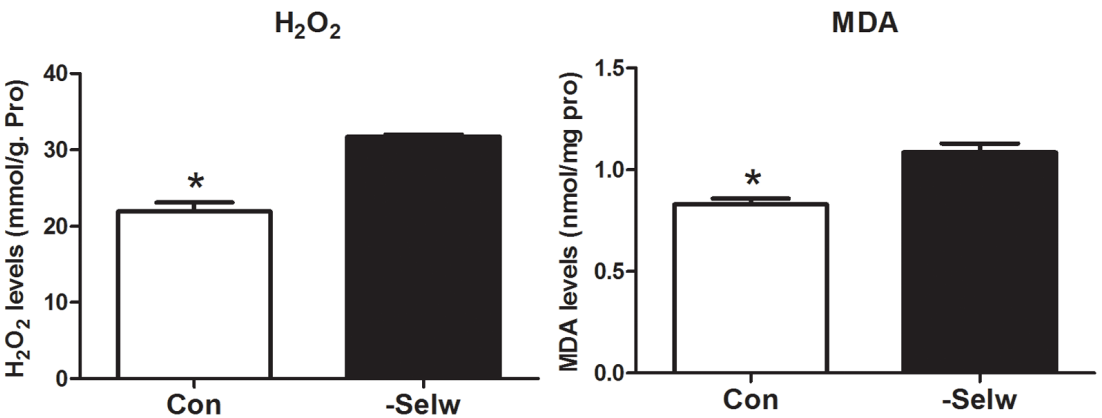

Figure 6: Enzymes activity detection. A. Enzymes activities in chicken muscles; B. Enzymes activities in embryos. Enzymes activities were assessed using Student's $t$-test. The data are expressed as the means $\pm \mathrm{SD}, n=5$. * shows the significant difference, $P<0.05$. 


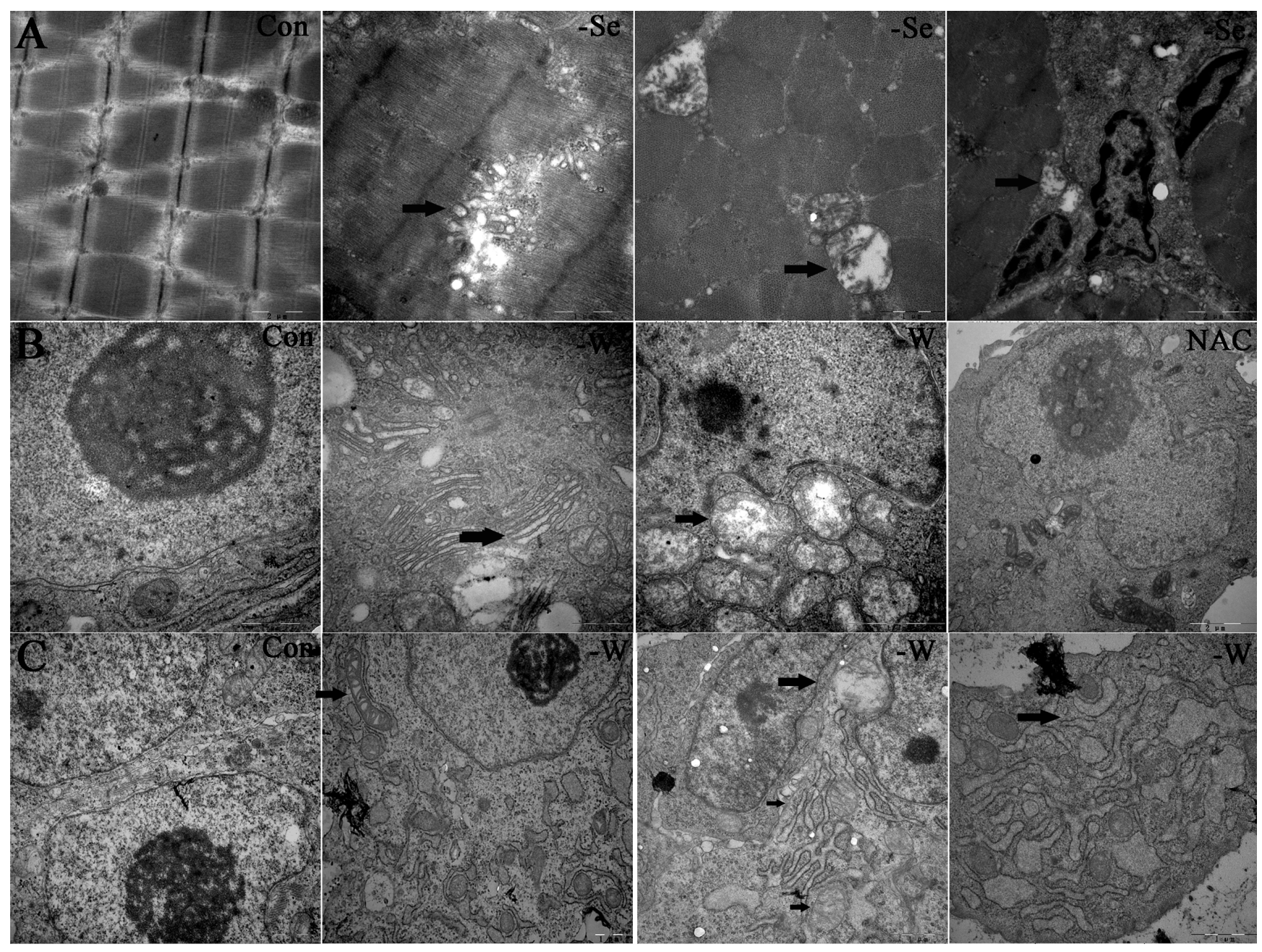

Figure 7: Ultrastructure detected by electron microscopy. A. Ultrastructure for chicken muscles; B. ultrastructure for myoblasts; and C. ultrastructure for embryo muscles. Black arrows show the mitochondrial swelling, vacuolization, and disruption of mitochondrial cristae, typical apoptosis structure, the swollen and dilated SR. 15000-40000 $\times$ magnification, $-\mathrm{W}$ is - SelW, NAC is - SelW/NAC.
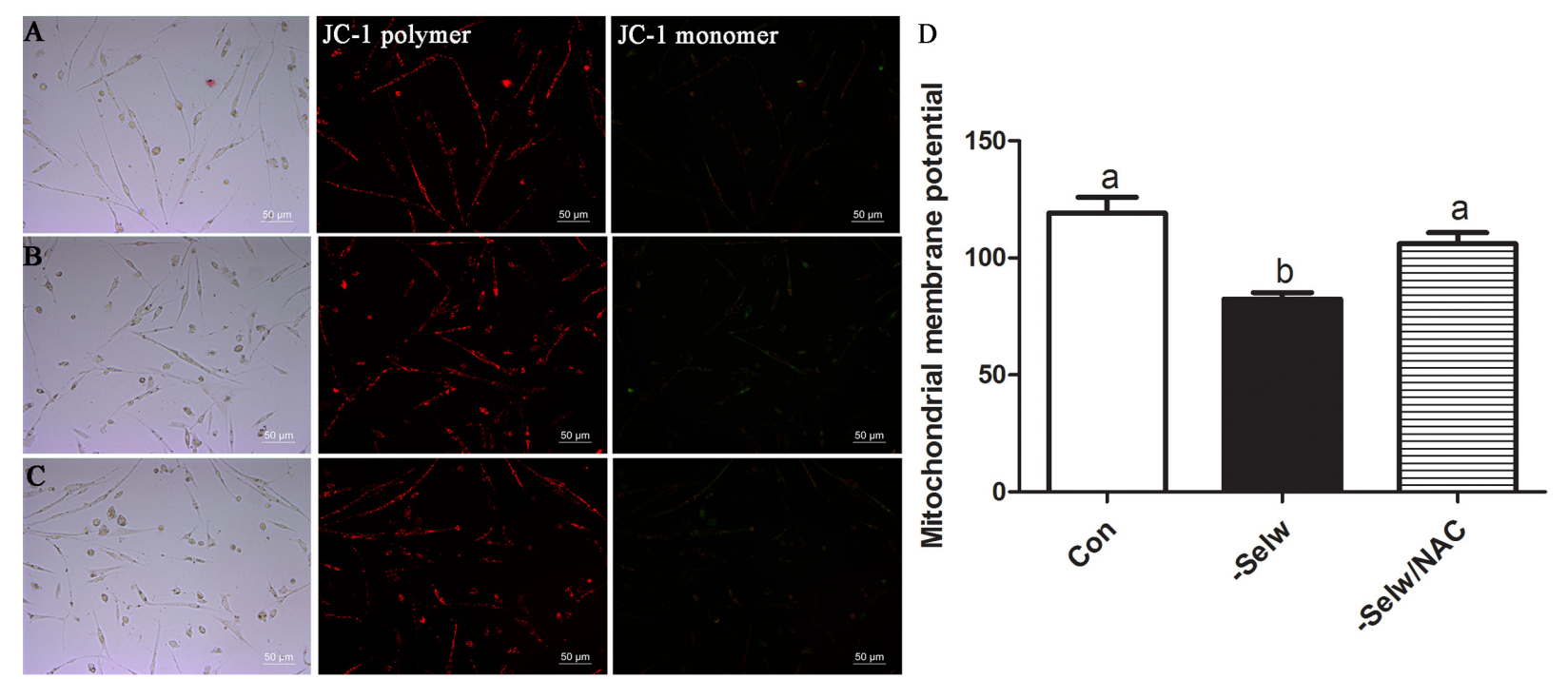

Figure 8: Mitochondrial membrane potentials $(\Delta \Psi \mathbf{m})$. A. $\Delta \Psi \mathrm{m}$ of Con; B. $\Delta \Psi \mathrm{m}$ of -SelW; C. $\Delta \Psi \mathrm{m}$ of -SelW/NAC. (A-C) $\Delta \Psi \mathrm{m}$ monitored by fluorescent microscope: red fluorescence indicates the aggregates, JC-1, while green fluorescence indicates the monomer; D. $\Delta \Psi \mathrm{m}$ monitored by Multimode Plate Readers. $\Delta \Psi \mathrm{m}$ in myoblasts were assessed using one-way ANOVA. The data are expressed as the means $\pm \mathrm{SD}, n=5$. Different lowercase letters show the significant difference, $P<0.05$. 
the hypothesis that $\mathrm{Ca}^{2+}$ disruption was involved in the muscle disease induced by Se deficiency. To the extent of our knowledge, this is the first report to show the effect of Se deficiency on $\mathrm{Ca}^{2+}$ signal in chicken muscles.

$\mathrm{Ca}^{2+}$ signal in muscles is tightly regulated by several types of $\mathrm{Ca}^{2+}$ channels and other molecules [7]. The disruption of $\mathrm{Ca}^{2+}$ channels will influence the $\mathrm{Ca}^{2+}$ signal, and induce $\mathrm{Ca}^{2+}$ channelopathies [7, 21-25]. Several previous studies showed the direct or indirect link of $\mathrm{Ca}^{2+}$ leak or disruption with TRPCs and NCX [26]; SERCA, RyRs, and NCX [27, 28]; STIM1 [29]; and PMCA or SERCA [30]. However, less documentation about the effect of Se deficiency on $\mathrm{Ca}^{2+}$ signal in chicken muscles is available. In the present study, we selected 10 $\mathrm{Ca}^{2+}$ channels and hoped to screen out one or some $\mathrm{Ca}^{2+}$ channels related to Se deficiency muscle injuries. The results showed that Se deficiency decreased the expression of SLC8A, CACNA1S, ORAI1, STIM1, SERCA, TRPC1, and TRPC3; increased the expression of PMCA; and did not influence RyR1 and RyR3 levels. The reduced extracellular $\mathrm{Ca}^{2+}$-entry channels and SERCA may well explain the $\mathrm{Ca}^{2+}$ leak in muscles; however, $\mathrm{Ca}^{2+}$ leak may also influence the levels of some $\mathrm{Ca}^{2+}$ channels [26, 31]. Therefore, the relationship between altered $\mathrm{Ca}^{2+}$ channels and $\mathrm{Ca}^{2+}$ leak in muscles is a complex. Excepting the close relationship of TRPCs, STIM1, and SLC8A channels with $\mathrm{Ca}^{2+}$ leak, the most important $\mathrm{Ca}^{2+}$ channels involved in the regulation of $\mathrm{SR} \mathrm{Ca}^{2+}$ levels are RyRs and SERCA [28]. In addition, RyRs, TRPCs and SERCA are less reported $\mathrm{Ca}^{2+}$ channels to be related to Se treatment [32, $33]$ and redox regulation activities [34, 35]. The present study concluded that the $\mathrm{Ca}^{2+}$ channels TRPC1, TRPC3, STIM1, SLC8A, SERCA, PMCA1, and CACNA1S are involved in Se deficiency-induced $\mathrm{Ca}^{2+}$ leak. Compared with previous studies, we reported two new $\mathrm{Ca}^{2+}$ channels, PMCA1 and CACNA1S that were related to Se deficiency and $\mathrm{Ca}^{2+}$ leak but found that RyRs were not involved in the Se deficiency-induced $\mathrm{Ca}^{2+}$ leak.

Another possible link between Se deficiency and $\mathrm{Ca}^{2+}$ disruption is the selenoproteins. Selenoproteins, such as SelN, SelM, SelT, SelK, SelW, and Txnrd, have either direct or indirect relation with $\mathrm{Ca}^{2+}$ signal and/ or $\mathrm{Ca}^{2+}$ channels regulation [3, 8-12, 32]. Among the 19 selenoproteins decreased by Se deficiency in broiler chicken muscles [20], only Txnrd2, Txnrd3, SelK, and SelW were reported to relate to $\mathrm{Ca}^{2+}$ regulation. Among these, SelW has a close relationship with the biological function and injuries of muscles [3, 17, 36, 37]. In the present study, we selected SelW as the primary candidate selenoprotein. After the deficiency of SelW was induced, primary myoblasts showed reduced $\mathrm{Ca}^{2+}$ levels in cytoplasm and SR, but accumulation in mitochondria. Similar to the myoblast, SelW knockdown in embryo muscles also induced $\mathrm{Ca}^{2+}$ leak. In addition, SelW deficiency also induced typical SR and mitochondrial injuries, which were closely related to $\mathrm{Ca}^{2+}$ leak, oxidative stress, and disordered $\mathrm{Ca}^{2+}$ channels $[18,38]$. Both in vivo and in vitro experiments indicated that $\mathrm{Ca}^{2+}$ leak and the related muscles injuries occur subsequent to SelW deficiency, which supported the idea that SelW deficiency is actively involved in the mechanism of Se deficiencyinduced $\mathrm{Ca}^{2+}$ leak in muscles. However, by detecting the response of $\mathrm{Ca}^{2+}$ channels to SelW deficiency, we found that SelW deficiency also influenced the $\mathrm{Ca}^{2+}$ channels. In myoblasts, SelW deficiency reduced RyR1, RyR3, SERCA, CACNA1S, TRPC1, TRPC3, STIM1 and ORAI1 $\mathrm{Ca}^{2+}$ channels. In embryos, SelW deficiency reduced SLC8A, CACNA1S, ORA1, TRPC1, and TRPC3 $\mathrm{Ca}^{2+}$ channels. The effect of SelW deficiency on CACNA1S, ORA1, TRPC1, and TRPC3 was similar to the treatment of Se deficiency. Therefore, SelW may play roles in the Se deficiency-induced $\mathrm{Ca}^{2+}$ leak by regulating the expressions of some typical $\mathrm{Ca}^{2+}$ channels.

How Se and SelW deficiency influenced the $\mathrm{Ca}^{2+}$ signal and the $\mathrm{Ca}^{2+}$ channels remains an unsolved question. In the present study, we treated myoblasts with different $\mathrm{Ca}^{2+}$ channel inhibitors and an activator to check the response of cells. The effect of ryanodine, $\mathrm{Ni}, \mathrm{Cd}$, and thapsigargin on cells was different. SelW deficiency reduced the response of RyR1 to ryanodine, increased the sensitivity of SERCA to thapsigargin, and CACNA1S to $\mathrm{Cd}$, or sustained and delayed the effect of Ni on NCX. However, caffeine does not induce any change in response in the control or siRNA cells. Therefore, the expression levels were influenced by SelW, as were the activities of some $\mathrm{Ca}^{2+}$ channels. As SelW is the typical antioxidative selenoprotein in myoblast, the redox regulation role may link SelW closely with these $\mathrm{Ca}^{2+}$ channels. In addition, oxidative stress was detected in Se deficiency chicken muscles and SelW knockdown embryo muscles and myoblasts [16, 17]. Therefore, oxidative stress closely linked SelW with Se deficiency-related injury. Following this, we treated the siRNA cells with NAC, a typical antioxidant. The results showed that NAC treatment alleviated the effect of SelW deficiency on RyR1, RyR3, SERCA, STIM1, CACNA1S, TRPC1, and TRPC3. Therefore, these $\mathrm{Ca}^{2+}$ channels were regulated by SelW in a redox-dependent manner. As in the $\mathrm{Ca}^{2+}$ channels, the $\mathrm{Ca}^{2+}$ levels in cytoplasm and mitochondria and the ROS levels [17] recovered to the normal levels. Even in $\mathrm{SR}, \mathrm{Ca}^{2+}$ leak was alleviated by NAC treatment. In addition, the SR and mitochondria injuries induced by SelW deficiency were also alleviated by NAC treatment. Therefore, the regulation of $\mathrm{Ca}^{2+}$ by SelW was partially dependent on the redox regulation function of SelW. This agrees with previous studies showing that redox activities of some $\mathrm{Ca}^{2+}$ channels, such as SERCA, RyR1, and TRPC1 [34, 35], could be regulated by antioxidant or oxidant $[18,39]$. Therefore, redox-regulated SERCA, CACNA1S, TRPC1, and TRPC3 channels by SelW may 
be involved in the process of Se deficiency-induced $\mathrm{Ca}^{2+}$ leak.

An important unanswered question that emerges from our experimentation is how SelW related $\mathrm{Ca}^{2+}$ leak functions with its redox regulation. One possible explanation in this context is that the SelW deficiency may decrease the antioxidative ability of myoblast [17] and muscles, and then this increased oxidative stress regulates the activation of $\mathrm{Ca}^{2+}$ channels such as SERCA and TRPCs, and leads to $\mathrm{Ca}^{2+}$ leak. In contrast, $\mathrm{Ca}^{2+}$ leak induced by SelW deficiency increased the accumulation of $\mathrm{Ca}^{2+}$ in mitochondria, and then this increased mitochondrial $\mathrm{Ca}^{2+}$ led to the production of reactive oxygen species [17, 34] and decreased mitochondrial membrane potential or increased mitochondrial damage [34]. Therefore, the SelW deficiency induced a vicious circle of molecular changes in muscles. By redox regulation function, SelW associated to SR and mitochondria together in the SelW deficiencyinduced $\mathrm{Ca}^{2+}$ leak and oxidative stress.

In summary, the typical pathological changes of skeletal muscles $\mathrm{Ca}^{2+}$ leak can be successfully replicated by solo feeding broiler chicken with a Se-deficient diet. In this process, Se deficiency primarily decreased the extracellular $\mathrm{Ca}^{2+}$-entry channels and SERCA, and influenced the $\mathrm{Ca}^{2+}$ signals. In addition, SelW deficiency induced the $\mathrm{Ca}^{2+}$ leak in both in vitro myoblast and in vivo embryo muscles, and influenced the $\mathrm{Ca}^{2+}$ channels in embryo muscles, which indicates that SelW is involved in the process of $\mathrm{Ca}^{2+}$ leak induced by Se deficiency. In the present study, we screened $\mathrm{Ca}^{2+}$ channels: TRPC1, TRPC3, STIM1, ORA1, SLC8A, SERCA, PMCA1, and CACNA1S in chicken muscles and SLC8A, CACNA1S, ORA1, TRPC1, and TRPC 3 in myoblasts and embryos that were involved in the $\mathrm{Ca}^{2+}$ leak. By treating the myoblasts with different $\mathrm{Ca}^{2+}$ channel inhibitors and NAC, we also found that redox-regulation role of SERCA, CACNA1S, TRPC1, and TRPC 3 by SelW was closely related to $\mathrm{Ca}^{2+}$ leak. We concluded that SelW plays an important role in the Se deficiency-induced muscles $\mathrm{Ca}^{2+}$ leak.

\section{MATERIALS AND METHODS}

\section{Birds and diets}

All procedures used in this study were approved by the Institutional Animal Care and Use Committee of Northeast Agricultural University [20]. A total of 180 oneday-old male broiler chicks (Weiwei Co. Ltd., Harbin, China) were randomly divided into two groups (90 chickens per group). Over the entire experimental period, the chickens were allowed ad libitum consumption of feed and water. The chickens were maintained on either a Sedeficient diet (-Se group) containing $0.008 \mathrm{mg} \mathrm{Se} / \mathrm{kg}$ or a sodium selenite diet (Control group) containing $0.2 \mathrm{mg} \mathrm{Se} /$ $\mathrm{kg}$. Each group was separated into six pens ( 15 chickens each pen). Chickens were killed at 25-30 days old. Following euthanasia with sodium pentobarbital, pectoral muscles were quickly removed. The tissues were rinsed with ice-cold sterile deionized water, frozen immediately in liquid nitrogen, and stored at $-80^{\circ} \mathrm{C}$ until needed.

\section{Cell culture and treatment}

Primary cultures of chicken embryo-driven myoblasts were prepared as described [17]. Briefly, myoblasts were isolated from the pectoral muscle of 12-day-old chicken embryos and digested with $0.1 \%$ collagenase I (Invitrogen, Carlsbad, CA, USA). The cell suspension was washed twice and separated with Percoll (Pharmacia, Uppsala, Sweden). The myoblasts were seeded into gelatin-coated six-well culture plates at a density of $12 \times 10^{4} \mathrm{cells} / \mathrm{cm}^{2}$ and were allowed to proliferate for $24 \mathrm{~h}$ in $5 \% \mathrm{CO}_{2}$ at $37^{\circ} \mathrm{C}$. Later, the differentiation of myoblasts was induced by replacing the proliferation medium with differentiation medium.

After the chicken myoblasts were plated in six-well plates at $70-80 \%$ confluence, the cells were transfected with $3 \mu \mathrm{L}$ of $20 \mu \mathrm{M}$ siRNAs and $3 \mu \mathrm{L}$ of Lipofectamine RNAiMAX Reagent (Invitrogen) in $2 \mathrm{~mL}$ of Opti-MEM. After transfection for approximately $48 \mathrm{~h}$, the cells were harvested for analysis. In the N-acetyl-L-cysteine (NAC) group, the cells were co-incubated with $2.5 \mathrm{mM} \mathrm{NAC}$ for $6 \mathrm{~h}$ after transfection and then harvested for analysis.

\section{Cas9 plasmid construction and injection in chicken embryo}

CRISPR/Cas9 plasmid for SelW was constructed by Inovogen Tech. Co., and the gRNA sequences for SelW are shown in Table 1. The jetPEITM (Polyplus-transfection Inc. USA) was used to deliver plasmids into chicken embryo and used nitrogen/phosphate (N/P) ratio of 8 to calculate amount of JetPEI required, as adopted by Jordan [40]. Chicken embryos at Stage $X$ of development [41] were selected, and a 2-3 $\mu \mathrm{L}$ mixture of plasmid and jetPEI ${ }^{\mathrm{TM}}$ was introduced beneath the blastoderm. One week following the introduction of the mixture, muscles were frozen immediately in liquid nitrogen, and stored at $-80^{\circ} \mathrm{C}$ until required. The DNA sequence of SelW was sequenced by Huada Gene Co., and the knockdown efficiency of SelW was detected by western blot technology.

\section{Quantitative real-time PCR (qPCR) analysis of mRNA levels}

Total RNA was isolated [2] from muscles, myoblasts, and embryos using TRIzol reagent according to the manufacturer's instructions (Invitrogen, Shanghai, 
Table 1: Sequences for Cas9 gRNA

\begin{tabular}{|l|l|}
\hline & Sequence $\left(\mathbf{5}^{\prime} \mathbf{- 3} \mathbf{}\right)$ \\
\hline gRNA1 & CTGCTTCCAGAACCCGCGCA \\
\hline gRNA2 & CCGGTGCCGTGCGCGGGTTC \\
\hline gRNA3 & CCAGAGCTCGCGTTCCAACC \\
\hline gRNA4 & GCCAAACTGCAGCGCATCG \\
\hline
\end{tabular}

Table 2: Primers used in the present study

\begin{tabular}{|l|l|l|}
\hline Genes & Forward primer $\left(\mathbf{5}^{\prime} \mathbf{- 3} \mathbf{\prime}\right)$ & Reverse primer $\left(\mathbf{5}^{\prime} \mathbf{- 3} \mathbf{\prime}\right)$ \\
\hline RyR1 & AGCCGAGCGTGGTCTATTAC & GAGGCAGTTGTAGCCGATGA \\
\hline RyR3 & TGGTTGAGGTAATGGCAGAA & TCTCCTTGGCTGTGAGTGTG \\
\hline SERCA1s & CCCTGGTCACAACTCTGCTG & GTCAGTGGAACCTTGGCTGT \\
\hline SLC8A1 & ACCGCTTCATGTCCTCCA & ATGAGCCCAAAGCCATCA \\
\hline PMCA1 & GATGGAAGGCTCTGGAAGG & TTCAGTGGCTGCATTTCC \\
\hline CACNA1S & CGAGGCCATGCTCAAGAT & CCAGGGAAACGATGGAGA \\
\hline TRPC1 & CGCTACCTCCACCTTTCAAT & CGTTTCACTTTGCCACTCG \\
\hline TRPC3 & GCAATCAGCAAGGGCTACAT & GTGCCGTCTTCGTCATAGG \\
\hline STIM1 & CGGCTTCCAGATCGTCAA & CATCCAGGTCATCCACGTC \\
\hline ORAI1 & GAGGTGGTGTTGCTGTGTTG & CTGCCTGTCCTGATGTGATG \\
\hline$\beta$-actin & CCGCTCTATGAAGGCTACGC & CTCTCG GCTGTGGTGGTGAA \\
\hline GAPDH & AGAACATCATCCCAGCGT & AGCCTTCACTACCCTCTTG \\
\hline
\end{tabular}

China). The RNA preparation, qPCR, and relative mRNA abundance quantification procedures were the same as previously described [16]. The amplification efficiency for each gene was determined using the DART-PCR program [42]. The relative abundance of mRNA was also calculated [43] to account for gene-specific efficiencies and was normalized to the mean expression of GAPDH and $\beta$-actin.

Primer Premier Software (Premier Biosoft International, USA) was used to design specific primers based on known chicken sequences (Table 2).

\section{Western blot analysis}

Protein extracts from the muscles, myoblasts, and embryos were subjected to SDS-polyacrylamide gel electrophoresis under reducing conditions. Separated proteins were then transferred to nitrocellulose membranes using a tank transfer for $2 \mathrm{~h}$ at $200 \mathrm{~mA}$ in Tris-glycine buffer containing 20\% methanol. The membranes were blocked with $5 \%$ skim milk for $2 \mathrm{~h}$, and then incubated over night with diluted primary antibodies against SERCA (1:1000, Immunoway Biotechnology Company, USA) and SelW (made by our lab) followed by a horseradish peroxidase (HRP)-conjugated secondary antibody against rabbit $\operatorname{IgG}$ (1:3000, Santa Cruz Biotechnology, USA). To verify equivalent loading of samples, the membrane was incubated with monoclonal $\beta$-actin antibody $(1: 1000$, Santa Cruz Biotechnology, USA), followed by an HRP- conjugated goat anti-mouse IgG (1:3000). The signal was detected using an enhanced chemiluminescence system (Cheml Scope5300, Clinx Science Instruments, Shanghai, China).

\section{Histological analysis of muscles}

Histological analysis was performed according to our previous study [44]. After necropsy, the muscle tissue specimens were rapidly fixed in $10 \%$ neutral buffered formalin solution for at least $24 \mathrm{~h}$. Fixed specimens were processed using the conventional paraffin-embedding technique. From the prepared paraffin blocks, sections were obtained and stained with hematoxylin and eosin (HE) for light microscopic examination.

\section{Determination of $\mathrm{Ca}^{2+}$ levels in chicken muscles}

To determine the levels of $\mathrm{Ca}^{2+}$ in the chicken muscles, inductively coupled plasma mass spectrometry ICP-MS (Thermo iCAPQ, American) was used. The instrumental parameters of the equipment used are summarized in Table 3.

The $\mathrm{Ca}^{2+}$ concentrations were determined in by an acid digest of samples according to the method of Uluozlu et al. [45]. One gram of each sample was digested with 5 $\mathrm{mL} \mathrm{HNO}_{3}(65 \%)$ and $2 \mathrm{~mL} \mathrm{H}_{2} \mathrm{O}_{2}(30 \%)$ in a microwave digestion system and diluted to $10 \mathrm{~mL}$ with deionized 
Table 3: Instrumental parameters for the ICP-MS

\begin{tabular}{|l|c|}
\hline \multicolumn{1}{|c|}{ Items } & Parameters \\
\hline Frequency $(\mathrm{MHz})$ & 27.12 \\
\hline Reflect power $(\mathrm{kW})$ & 1.55 \\
\hline Sampling depth $(\mathrm{mm})$ & 5.0 \\
\hline Torch-H $(\mathrm{mm})$ & 0.01 \\
\hline Torch-V $(\mathrm{mm})$ & -0.39 \\
\hline Carrier gas $(\mathrm{L} / \mathrm{min})$ & 1.05 \\
\hline Nebuliser pump $(\mathrm{rpm})$ & 40 \\
\hline S/C temperature $\left({ }^{\circ} \mathrm{C}\right)$ & 2.7 \\
\hline Oxide ions $(156 / 140)$ & $<2.0 \%$ \\
\hline Doubly charged $(70 / 140)$ & $<3.0 \%$ \\
\hline Nebuliser type & Concentric \\
\hline
\end{tabular}

water. A blank digest was carried out in the same way. All sample solutions were clear. Digestion conditions for the microwave system were applied as $1800 \mathrm{~W}$ for $3 \mathrm{~min}$ at $100^{\circ} \mathrm{C}, 1800 \mathrm{~W}$ for $10 \mathrm{~min}$ at $150^{\circ} \mathrm{C}$, and $1800 \mathrm{~W}$ for 45 min at $180^{\circ} \mathrm{C}$. All digested samples were filled with ultrapure water to the final volume before analysis by ICP-MS.

\section{$\mathrm{Ca}^{2+}$ image in muscle tissue with $\mathrm{SR} \mu-\mathrm{XRF}$}

$\mathrm{Ca}^{2+}$ localization in muscle tissues were surveyed with synchrotron radiation micro X-ray fluorescence (SR $\mu-X R F)$. Muscle tissue specimens were rapidly fixed in $10 \%$ neutral-buffered formalin solution for at least $24 \mathrm{~h}$. Fixed specimens were dehydrated through a graded series of ethanol, cleared in xylene, embedded in paraffin, and then cut into $5 \mathrm{~mm}$-thick sections. The slices were fixed onto a $1 \mathrm{~mm}$-thick glass slide, and then analyzed by $\mathrm{SR} \mu$ XRF according to the method of Li [46].

\section{Determination of $\mathrm{Ca}^{2+}$ level in cells}

The cells were cultured in $35 \mathrm{~mm}$ glass-bottomed dishes and loaded for $30-60 \mathrm{~min}\left(37^{\circ} \mathrm{C}\right)$ with three different $\mathrm{Ca}^{2+}$ fluorescence indicators: $5 \mu \mathrm{M}$ Fluo3 acetoxymethylester (AM) (Beyotime Institute of Biotechnology, Haimen, China) for the cytoplasm, 10 $\mu \mathrm{M}$ Rhod2 (Invitrogen) for the mitochondria [47], and 5 $\mu \mathrm{M}$ Fluo5N AM (Invitrogen) for the SR [48-50]. Rhod2 has a net positive charge, which promotes preferential sequestration in the mitochondria due to potential-driven uptake, whereas Fluo5N promotes dye accumulation within the SR [49]. To remove the cytosolic Rhod2 and Fluo $5 \mathrm{~N}$, the cells were permeabilized with $10 \mu \mathrm{M}$ digitonin according to the method described previously [47]. To estimate the Rhod 2 fluorescence pattern in live mitochondria, Mito-Tracker Green (Beyotime Institute of Biotechnology, Haimen, China) was used for mitochondrial marking [51]. In addition, we used ER-Tracker Red (Beyotime Institute of Biotechnology,
Haimen, China) to mark SR [52]. Cells were washed three times and left in Tyrode's solution (in mM: $140 \mathrm{NaCl}, 5.4$ $\mathrm{KCl}, 1.8 \mathrm{CaCl}_{2}, 0.5 \mathrm{MgCl}_{2}, 10$ Hepes, and 5.6 glucose, $\mathrm{pH}$ $=7.4$ ) for $10 \mathrm{~min}$ until the cell fluorescence equilibrated. Images were acquired using excitation wavelengths of $488 \mathrm{~nm}$ for Fluo3, Fluo5N, and Mito-Tracker Green and 563-587 nm for Rhod2 and ER-Tracker Red. The signals were collected at 505-530 nm for Fluo3, Fluo5N and Mito Tracker Green and at $590 \mathrm{~nm}$ for Rhod2 and ER-Tracker Red. After the cell fluorescence was equilibrated and stabilized, $\mathrm{Ni}$, ryanodine, $\mathrm{Cd}$, caffeine, and thapsigargin were added to the cells, and the fluorescence was collected and imaged with a confocal laser scanning microscope, (Fluoview ${ }^{\mathrm{TM}}$ FV 1000) using a $40 \times$ oil lens, and analyzed using the Olympus Fluoview Ver. 2.0a Viewer software. The fluorescence intensity levels are presented relative to baseline and shown as $\mathrm{F} / \mathrm{F}_{0}$, where $\mathrm{F}_{0}$ is the initial fluorescence as described previously [53]. Fluorescence data were collected from an average of 8-12 cells per experiment.

\section{Determination of $\mathrm{Ca}^{2+}$ level in embryo skeletal muscle}

Embryo muscle samples were homogenized on ice in physiological saline and centrifuged at $700 \times g$ to collect supernatants. $\mathrm{Ca}^{2+}$ levels were determined using the assay kits (Nanjing Jiancheng Bioengineering Institute). Protein levels were determined using the protein assay kit (Nanjing Jiancheng Bioengineering Institute). The biochemical assays were performed according to the manufacturer's instructions with a UV-visible spectrophotometer (T6 Xinyue, Beijing).

\section{Antioxidative enzyme activity and oxidative injuries assays}

Chicken and embryo muscle samples were homogenized on ice in physiological saline and 
centrifuged at $700 \times g$ to collect supernatants for the biochemical assays. GPx, SOD, and CAT activities; MDA concentration; $\mathrm{H}_{2} \mathrm{O}_{2}$ levels; and protein concentrations were determined according to the kit's instructions (Nanjing Jiancheng Bioengineering Institute, China) and were recorded with Multimode Plate Readers (TECAN Infinite M200 PRO, Switzerland).

\section{Detection of mitochondrial membrane potential in myoblasts}

The mitochondrial membrane potential was monitored using 5, 5', 6, 6'- tetra-chloro-1, 1', 3, 3 '-tetraethylbenzimidazolyl-carbocyanine iodide (JC-1), a lipophilic cationic fluorescence dye (Beyotime Institute of Biotechnology, Haimen, China) [54, 55]. Cells were incubated with the $\mathrm{JC}-1$ staining solution at $37^{\circ} \mathrm{C}$ for 20 min and rinsed twice with JC-1 buffer. The mitochondrial membrane potentials were monitored by determining the relative amounts of the dual emissions from the mitochondrial JC-1 monomers and polymers using an Olympus fluorescence microscope and a Multimode Plate Reader (TECAN Infinite M200 PRO, Switzerland). The JC-1 monomer has an excitation wavelength of $490 \mathrm{~nm}$ and emission wavelength of $530 \mathrm{~nm}$. The JC-1 polymer has an excitation wavelength of $525 \mathrm{~nm}$ and emission wavelength of $590 \mathrm{~nm}$. With low mitochondrial membrane potential, JC-1 existed mainly as a monomer, showing a green fluorescence. JC-1 forms aggregate and emit red fluorescence whenever the mitochondrial membrane potential was high. The mitochondrial membrane potential was indicated by the green to red fluorescence intensity ratio.

\section{Sections for electron microscopy}

The technique adopted to observe ultrastructural changes was similar to that of our previous study [44]: the collected samples were fixed immediately in $2.5 \%$ glutaraldehyde in phosphate-buffered saline (v/v, pH 7.2), post-fixed in $1 \%$ osmium tetroxide (v/v), and stained with $4.8 \%$ uranyl acetate following dehydration. The samples were washed in propylene oxide and impregnated with epoxy resins. The semi-fine sections were contrasted with uranyl acetate and lead citrate for study via microscopy. The microphotographs were taken with a transmission electron microscope (TEM).

\section{Statistical analysis}

The data analysis was performed using SPSS statistical software for Windows (version13; SPSS Inc., Chicago, IL, USA). Differences between different groups were assessed using Student's $t$-test or one-way ANOVA.
The data are expressed as the means \pm standard deviation. Differences were considered to be significant at $P<0.05$.

\section{ACKNOWLEDGMENTS}

This study was supported by the International (Regional) Cooperation and Exchange Projects of the National Natural Science Foundation of China (31320103920) and the National Natural Science Foundation of China (31272626). All authors read and approved the final manuscript.

\section{CONFLICTS OF INTEREST}

The authors declare that there are no conflicts of interest.

\section{REFERENCES}

1. Bellinger FP, Raman AV, Reeves MA and Berry MJ. Regulation and function of selenoproteins in human disease. Biochem J. 2009; 422:11-22.

2. Yao HD, Wu Q, Zhang ZW, Zhang JL, Li S, Huang JQ, Ren FZ, Xu SW, Wang XL and Lei XG. Gene expression of endoplasmic reticulum resident selenoproteins correlates with apoptosis in various muscles of se-deficient chicks. J Nutr. 2013; 143:613-619.

3. Lescure A, Rederstorff M, Krol A, Guicheney P and Allamand V. Selenoprotein function and muscle disease. Biochim Biophys Acta. 2009; 1790:1569-1574.

4. Rederstorff M, Krol A and Lescure A. Understanding the importance of selenium and selenoproteins in muscle function. Cell Mol Life Sci. 2006; 63:52-59.

5. Huang JQ, Li DL, Zhao H, Sun LH, Xia XJ, Wang KN, Luo $\mathrm{X}$ and Lei $\mathrm{XG}$. The selenium deficiency disease exudative diathesis in chicks is associated with downregulation of seven common selenoprotein genes in liver and muscle. J Nutr. 2011; 141:1605-1610.

6. J. Krebs. (2007). Calcium: A Matter of Life or Death: Elsevier.

7. Lee EH. Ca2+ channels and skeletal muscle diseases. Progress in biophysics and molecular biology. 2010; 103:35-43.

8. Verma S, Hoffmann FW, Kumar M, Huang Z, Roe $\mathrm{K}$, Nguyen-Wu E, Hashimoto AS and Hoffmann PR. Selenoprotein K knockout mice exhibit deficient calcium flux in immune cells and impaired immune responses. J Immunol. 2011; 186:2127-2137.

9. Sandrine A and Ana F. Selenoproteins and Protection against Oxidative Stress. Antioxidants \& redox signaling. 2010; 12 .

10. Reeves MA, Bellinger FP and Berry MJ. The Neuroprotective Functions of Selenoprotein M and its Role in Cytosolic Calcium Regulation. Antioxidants \& redox 
signaling. 2010; 12.

11. Grumolato L, Ghzili H, Montero-Hadjadje M, Gasman S, Lesage J, Tanguy Y, Galas L, Ait-Ali D, Leprince J, Guerineau NC, Elkahloun AG, Fournier A, Vieau D, et al. Selenoprotein $\mathrm{T}$ is a PACAP-regulated gene involved in intracellular $\mathrm{Ca} 2+$ mobilization and neuroendocrine secretion. FASEB J. 2008; 22:1756-1768.

12. Jurynec MJ, Xia R, Mackrill JJ, Gunther D, Crawford T, Flanigan KM, Abramson JJ, Howard MT and Grunwald DJ. Selenoprotein $\mathrm{N}$ is required for ryanodine receptor calcium release channel activity in human and zebrafish muscle. Proc Natl Acad Sci U S A. 2008; 105:12485-12490.

13. Zhou JC, Zhao H, Li JG, Xia XJ, Wang KN, Zhang YJ, Liu Y, Zhao Y and Lei XG. Selenoprotein gene expression in thyroid and pituitary of young pigs is not affected by dietary selenium deficiency or excess. J Nutr. 2009; 139:10611066.

14. Zhou J, Huang K and Lei XG. Selenium and diabetesevidence from animal studies. Free Radic Biol Med. 2013; 65:1548-1556.

15. Whanger PD. Selenoprotein W: a review. Cell Mol Life Sci. 2000; 57: 1846-1852.

16. Yao HD, Liu W, Zhao WC, Fan RF, Zhao X, Khoso $\mathrm{PA}$, Zhang ZW and $\mathrm{Xu} \mathrm{SW}$. Different responses of selenoproteins to the altered expression of selenoprotein W in chicken myoblasts. RSC advances. 2014; 4:64032.

17. Yao HD, Wu Q, Zhang ZW, Li S, Wang XL, Lei XG and $\mathrm{Xu} \mathrm{SW}$. Selenoprotein $\mathrm{W}$ serves as an antioxidant in chicken myoblasts. Biochimica et biophysica acta. 2013; 1830:3112-3120.

18. Dowling JJ, Arbogast S, Hur J, Nelson DD, McEvoy A, Waugh T, Marty I, Lunardi J, Brooks SV, Kuwada JY and Ferreiro A. Oxidative stress and successful antioxidant treatment in models of RYR1-related myopathy. Brain. 2012; 135:1115-1127.

19. Arbogast S, Beuvin M, Fraysse B, Zhou H, Muntoni F and Ferreiro A. Oxidative stress in SEPN1-related myopathy: from pathophysiology to treatment. Ann Neurol. 2009; 65:677-686.

20. Yao H, Zhao W, Zhao X, Fan R, Khoso PA, Zhang Z, Liu $\mathrm{W}$ and $\mathrm{Xu}$ S. Selenium deficiency mainly influences the gene expressions of antioxidative selenoproteins in chicken muscles. Biological trace element research. 2014; 161:318327.

21. Kimura T, Nakamori M, Lueck JD, Pouliquin P, Aoike F, Fujimura H, Dirksen RT, Takahashi MP, Dulhunty AF and Sakoda S. Altered mRNA splicing of the skeletal muscle ryanodine receptor and sarcoplasmic/endoplasmic reticulum $\mathrm{Ca} 2+-\mathrm{ATPase}$ in myotonic dystrophy type 1 . Hum Mol Genet. 2005; 14:2189-2200.

22. Zucchi $\mathrm{R}$ and Ronca-Testoni $\mathrm{S}$. The sarcoplasmic reticulum $\mathrm{Ca} 2+$ channel/ryanodine receptor: modulation by endogenous effectors, drugs and disease states. Pharmacological reviews. 1997; 49:1-51.
23. Zhou H, Yamaguchi N, Xu L, Wang Y, Sewry C, Jungbluth H, Zorzato F, Bertini E, Muntoni F, Meissner G and Treves S. Characterization of recessive RYR1 mutations in core myopathies. Hum Mol Genet. 2006; 15:2791-2803.

24. Takamori M. Autoantibodies against TRPC 3 and ryanodine receptor in myasthenia gravis. Journal of neuroimmunology. 2008; 200:142-144.

25. Odermatt A, Barton K, Khanna VK, Mathieu J, Escolar D, Kuntzer T, Karpati G and MacLennan DH. The mutation of Pro789 to Leu reduces the activity of the fast-twitch skeletal muscle sarco(endo)plasmic reticulum $\mathrm{Ca} 2+$ ATPase (SERCA1) and is associated with Brody disease. Human genetics. 2000; 106:482-491.

26. Kojima A, Kitagawa H, Omatsu-Kanbe M, Matsuura $H$ and Nosaka S. Ca2+ paradox injury mediated through TRPC channels in mouse ventricular myocytes. Br J Pharmacol. 2010; 161:1734-1750.

27. Mackiewicz U and Lewartowski B. The effect of sarcoplasmic reticulum $\mathrm{Ca} 2+$ leak on contractile activity of guinea pig heart myocytes depends in activity of sarcoplasmic reticulum $\mathrm{Ca} 2+-\mathrm{ATPase}$ and $\mathrm{Na}+/ \mathrm{Ca} 2+$ exchanger. Journal of physiology and pharmacology. 2008; 59:287-300.

28. Morimoto S, Hongo K, Kusakari Y, Komukai K, Kawai M, J OU, Nakayama H, Asahi M, Otsu K, Yoshimura M and Kurihara S. Genetic modulation of the SERCA activity does not affect the $\mathrm{Ca}(2+)$ leak from the cardiac sarcoplasmic reticulum. Cell Calcium. 2014; 55:17-23.

29. Manjarres IM, Alonso MT and Garcia-Sancho J. Calcium entry-calcium refilling (CECR) coupling between storeoperated $\mathrm{Ca}(2+)$ entry and sarco/endoplasmic reticulum Ca(2+)-ATPase. Cell Calcium. 2011; 49:153-161.

30. Diederichs F. Ion homeostasis and the functional roles of SERCA reactions in stimulus-secretion coupling of the pancreatic beta-cell: A mathematical simulation. Biophysical chemistry. 2008; 134:119-143.

31. Vandebrouck C, Martin D, Colson-Van Schoor M, Debaix $\mathrm{H}$ and Gailly P. Involvement of TRPC in the abnormal calcium influx observed in dystrophic ( $\mathrm{mdx}$ ) mouse skeletal muscle fibers. J Cell Biol. 2002; 158:1089-1096.

32. Okatan EN, Tuncay E and Turan B. Cardioprotective effect of selenium via modulation of cardiac ryanodine receptor calcium release channels in diabetic rat cardiomyocytes through thioredoxin system. J Nutr Biochem. 2013; 24:2110-2118.

33. Naziroglu M, Ozgul C, Kucukayaz M, Cig B, Hebeisen S and Bal R. Selenium modulates oxidative stress-induced TRPM2 cation channel currents in transfected Chinese hamster ovary cells. Basic \& clinical pharmacology \& toxicology. 2013; 112:96-102.

34. Robert F. Feissner, Jolanta Skalska1, Gaum. WE and Sheu. S-S. Crosstalk signaling between mitochondrial Ca2+ and ROS. Front Biosci. 2009; 14:1197-1218.

35. Santiago E, Climent B, Munoz M, Garcia-Sacristan A, 
Rivera L and Prieto D. Hydrogen peroxide activates storeoperated $\mathrm{Ca}(2+)$ entry in coronary arteries. Br J Pharmacol. 2015; 172:5318-5332.

36. Noh OJ, Park YH, Chung YW and Kim IY. Transcriptional regulation of selenoprotein $\mathrm{W}$ by MyoD during early skeletal muscle differentiation. J Biol Chem. 2010; 285:40496-40507.

37. Aachmann FL, Fomenko DE, Soragni A, Gladyshev VN and Dikiy A. Solution structure of selenoprotein $\mathrm{W}$ and NMR analysis of its interaction with $14-3-3$ proteins. The Journal of biological chemistry. 2007; 282:37036-37044.

38. Dowling JJ, Vreede AP, Low SE, Gibbs EM, Kuwada JY, Bonnemann CG and Feldman EL. Loss of myotubularin function results in T-tubule disorganization in zebrafish and human myotubular myopathy. PLoS genetics. 2009; 5:e1000372.

39. Espinosa A, Leiva A, Pena M, Muller M, Debandi A, Hidalgo C, Carrasco MA and Jaimovich E. Myotube depolarization generates reactive oxygen species through $\mathrm{NAD}(\mathrm{P}) \mathrm{H}$ oxidase; ROS-elicited $\mathrm{Ca} 2+$ stimulates ERK, CREB, early genes. Journal of cellular physiology. 2006; 209:379-388.

40. Jordan BJ, Vogel S, Stark MR and Beckstead RB. Expression of green fluorescent protein in the chicken using in vivo transfection of the piggyBac transposon. Journal of biotechnology. 2014; 173:86-89.

41. Andacht $\mathrm{T}, \mathrm{Hu} \mathrm{W}$ and Ivarie R. Rapid and improved method for windowing eggs accessing the stage $\mathrm{X}$ chicken embryo. Molecular reproduction and development. 2004; 69:31-34.

42. Peirson SN, Butler JN and Foster RG. Experimental validation of novel and conventional approaches to quantitative real-time PCR data analysis. Nucleic Acids Res. 2003; 31 :e73.

43. Livak KJ and Schmittgen TD. Analysis of relative gene expression data using real-time quantitative PCR and the 2(-Delta Delta C(T)) Method. Methods. 2001; 25:402-408.

44. Shao JJ, Yao HD, Zhang ZW, Li S and Xu SW. The disruption of mitochondrial metabolism and ion homeostasis in chicken hearts exposed to manganese. Toxicol Lett. 2012; 214:99-108.

45. Uluozlu OD, Tuzen M, Mendil D and Soylak M. Assessment of trace element contents of chicken products from Turkey. Journal of hazardous materials. 2009; 163:982-987.
46. Li YF, Gao Y, Chai Z and Chen C. Nanometallomics: an emerging field studying the biological effects of metalrelated nanomaterials. Metallomics. 2014; 6:220-232.

47. Belmonte S and Morad M. 'Pressure-flow'-triggered intracellular $\mathrm{Ca} 2+$ transients in rat cardiac myocytes: possible mechanisms and role of mitochondria. J Physiol. 2008; 586:1379-1397.

48. Picht E, DeSantiago J, Blatter LA and Bers DM. Cardiac alternans do not rely on diastolic sarcoplasmic reticulum calcium content fluctuations. Circulation research. 2006; 99:740-748.

49. Zima AV, Picht E, Bers DM and Blatter LA. Termination of cardiac $\mathrm{Ca} 2+$ sparks: role of intra-SR $[\mathrm{Ca} 2+]$, release flux, and intra-SR Ca2+ diffusion. Circulation research. 2008; 103:e105-115.

50. Bovo E, Lipsius SL and Zima AV. Reactive oxygen species contribute to the development of arrhythmogenic $\mathrm{Ca}(2)(+)$ waves during beta-adrenergic receptor stimulation in rabbit cardiomyocytes. J Physiol. 2012; 590:3291-3304.

51. Quintanilla RA, Jin YN, Fuenzalida K, Bronfman M and Johnson GV. Rosiglitazone treatment prevents mitochondrial dysfunction in mutant huntingtin-expressing cells: possible role of peroxisome proliferator-activated receptor-gamma (PPARgamma) in the pathogenesis of Huntington disease. J Biol Chem. 2008; 283:25628-25637.

52. Kessel D, Castelli $M$ and Reiners JJ. Ruthenium redmediated suppression of $\mathrm{Bcl}-2$ loss and $\mathrm{Ca}(2+)$ release initiated by photodamage to the endoplasmic reticulum: scavenging of reactive oxygen species. Cell death and differentiation. 2005; 12:502-511.

53. Zherebitskaya E, Schapansky J, Akude E, Smith DR, Van der Ploeg R, Solovyova N, Verkhratsky A and Fernyhough P. Sensory neurons derived from diabetic rats have diminished internal $\mathrm{Ca} 2+$ stores linked to impaired reuptake by the endoplasmic reticulum. ASN neuro. 2012; 4.

54. Shen X, Liu L, Yin F, Ma H and Zou S. Effect of dehydroepiandrosterone on cell growth and mitochondrial function in TM-3 cells. General and comparative endocrinology. 2012; 177:177-186.

55. Zhang L, Ma J, Li Y, Guo L, Ran Y, Liu S, Jiang C and Zhu D. 15-Hydroxyeicosatetraenoic acid (15-HETE) protects pulmonary artery smooth muscle cells against apoptosis via HSP90. Life Sci. 2010; 87:223-231. 